\title{
Utilization of care during pregnancy in rural Guatemala: does obstetrical need matter?
}

\author{
Dana A. Glei ${ }^{\mathrm{a}, *}$, Noreen Goldman ${ }^{\mathrm{b}}$, Germán Rodríguez ${ }^{\mathrm{b}}$ \\ a Department of Demography, University of California, Berkeley, 1512 Pembleton Place, Santa Rosa, CA 95403-2349, USA \\ ${ }^{\mathrm{b}}$ Office of Population Research, Princeton University, Wallace Hall-2nd floor, Princeton, NJ 08544-2091, USA
}

\begin{abstract}
This study examines factors associated with the use of biomedical care during pregnancy in Guatemala, focusing on the extent to which complications in an ongoing or previous pregnancy affect a woman's decisions to seek care. The findings, based on multilevel models, suggest that obstetrical need, as well as demographic, social, and cultural factors, are important predictors of pregnancy care. In contrast, measures of availability and access to health services have modest effects. The results also suggest the importance of unobserved variables-such as quality of care-in explaining women's decisions about pregnancy care. These results imply that improving proximity to biomedical services is unlikely to have a dramatic impact on utilization in the absence of additional changes that improve the quality of care or reduce barriers to access. Moreover, current efforts aimed at incorporating midwives into the formal health-care system may need to extend their focus beyond the modification of midwife practices to consider the provision of culturally appropriate, high-quality services by traditional and biomedical providers alike.
\end{abstract}

(C) 2003 Elsevier Science Ltd. All rights reserved.

Keywords: Pregnancy; Prenatal care; Pregnancy complications; Biomedical care; Guatemala; Multilevel models

\section{Introduction}

Of the nearly 600,000 women who die each year due to pregnancy-related causes, over $99 \%$ live in developing countries (WHO \& UNICEF, 1996). An additional 50 million women in developing countries experience a pregnancy-related complication each year (NRC, 1997). These numbers reflect huge disparities in maternal morbidity and mortality between developing and industrialized countries, with rates in the former countries reaching values 100 times as large as those in the latter (Walsh, Feifer, Measham, \& Gertler, 1993).

Since the 1980s there has been increasing interest on the part of governments and international agencies in improving maternal and child health in poor countries. Many programs, such as the Safe Motherhood Initiative, developed in response to persistently high rates of

\footnotetext{
*Corresponding author. Tel.: +1-707-544-3006; fax: +1707-544-3006.

E-mail address: danaglei@pacbell.net (D.A. Glei).
}

maternal mortality and morbidity, limited training of birth attendants, and concentration of health services in major urban areas. The underlying premise of these initiatives is that the vast majority of infant and maternal deaths and disabilities are preventable through high-quality care, detection and efficient referral for complications, and access to the essential elements of obstetric care when needed (Mahler, 1987; Safe Motherhood IAG, 2000).

In this paper, we examine the use of pregnancy-related care in Guatemala, a country characterized by some of the highest maternal and infant mortality rates in Latin America. Recent estimates indicate a maternal mortality rate of 190 per 100,000 live births and an infant mortality rate of 43 per 1000 (World Bank, 1999). Although the use of government health services and private doctors and nurses has grown in recent decades, utilization of these biomedical services for pregnancyrelated care continues to be low relative to other Latin American countries (INE et al., 1996; WHO, 2001). This is especially true in rural areas where most births still 
occur at home, and prenatal care and delivery assistance are typically provided by midwives with little or no formal training (Lang \& Elkin, 1997; Goldman, Glei, Pebley, \& Delgado, 2001a).

During the 1980s, the Guatemalan Ministry of Health adopted WHO recommendations regarding the training of midwives ${ }^{1}$ to serve as extensions of maternal and child health services (Acevedo \& Hurtado, 1997; Leedam, 1985). A recent study indicates that the majority of Guatemalan midwives (comadronas) have attended training (Goldman \& Glei, 2003), during which they were encouraged to send all pregnant women to a government health facility for tetanus vaccination, prenatal examinations, and postpartum follow-up, and instructed to refer high-risk women and those with complications to a doctor or hospital (Cosminsky, 1977; Putney \& Smith, 1989). Nevertheless, most midwives (even trained ones) did not refer their clients to a biomedical provider (e.g., the staff of a government health facility or a private doctor) on a regular basis, and most pregnant women did not see a biomedical provider during pregnancy (Goldman \& Glei, 2003).

In this analysis we examine factors associated with the use of biomedical care during pregnancy in Guatemala in an effort to better understand the continued low utilization of biomedical services. We use detailed data collected in the 1995 Guatemalan Survey of Family Health (known by the Spanish acronym EGSF), which includes individual, community, and provider-level information for a random sample of rural Guatemalan communities and households. To the best of our knowledge, this survey provides a unique source of information for poor countries on the timing of use of different types of care during pregnancy and the timing of pregnancy-related complications. These data, collected using a monthly calendar format, permit us to estimate the extent to which use of biomedical prenatal care is concentrated among women with an obstetrical need for such care - a topic that has received relatively little attention in developing countries. In addition, the EGSF provides extensive information on many other factors hypothesized to affect utilization of pregnancyrelated services, such as the availability of traditional and biomedical health providers, previous pregnancy history, health beliefs, socioeconomic status, social networks, and community characteristics and infrastructure.

In the next section of the paper, we review previous studies on the determinants of pregnancy care that motivate the choice of explanatory variables included in our analysis. Next, we describe the data, analytic

\footnotetext{
${ }^{1}$ We use the term "midwife" rather than "traditional birth attendant" because the latter term is viewed by some as ethnocentric and medicocentric (Cosminsky, 2001a). In Guatemala, midwives are known as "comadronas".
}

strategy, and explanatory variables used in the multivariate models. In the final sections, we present the results from the statistical analysis and discuss their implications for pregnancy care in Guatemala.

\section{Determinants of pregnancy care}

\section{Accessibility and quality of health services}

The accessibility of health services is often cited as a critical determinant of health-care choice in the developing world (Timyan, Brechin, Measham, \& Ogunleye, 1993). Midwives have been the traditional providers of maternity care in Guatemala since pre-Hispanic times (Hurtado \& Sáenz de Tejada, 2001), are highly respected in most communities - though not among biomedical personnel (Cosminsky, 2001b), and are available in most communities, even in rural areas (Goldman \& Glei, 2003; INCAP et al., 1997). In contrast, biomedical services - particularly doctors and private clinics - tend to be concentrated in larger communities with greater economic resources and public infrastructure (Glei, 2001). Analyses from the demographic and health survey (DHS) showed an inverse relationship between proximity of a government-sponsored clinic and use of biomedical care during pregnancy in Guatemala (Pebley, Goldman, \& Rodríguez, 1996). Lack of transportation, the cost of transport, and the difficulty of walking for hours to the nearest government health facility may also pose problems for pregnant women (Acevedo \& Hurtado, 1997; Villatoro \& Hurtado, 1986).

The cost of services presents another important constraint on utilization. The average fee charged by doctors for pregnancy and delivery care is about ten times as high as the corresponding fees charged by midwives (Goldman \& Glei, 2003). Government-sponsored health centers and posts are the most affordable source of biomedical pregnancy care, offering prenatal care for free or at a nominal cost ( 5 cents US). Although access to health insurance or free health care (through non-governmental or religious organizations) could enhance access to non-governmental health services, the vast majority of rural Guatemalan women and their families do not have these alternatives (Goldman, Pebley, \& Gragnolati, 2002).

Even if services are accessible and affordable, people in developing countries are frequently unable to obtain needed medical supplies and face poor patient management and lack of know-how when they reach a health facility (Sundari, 1992). In Guatemala, health centers are typically run by a doctor and have a professional nurse on staff, but health posts offer more limited services and are usually managed by an auxiliary nurse with only $8-10$ months of training or a medical student. In addition, these facilities typically lack critical supplies 
and medicines (Goldman et al., 2001a; INCAP et al., 1997; MotherCare, 1997).

Good relations between midwives and biomedical providers are important for facilitating referrals, but in Guatemala these relations are often tense, in part due to social, ethnic, and cultural differences between providers (Hurtado \& Sáenz de Tejada, 2001). As in other societies (Geurts, 2001; Jenkins, 2001; Sesia, 1997), the relationship is asymmetric with biomedical providers occupying a privileged position within the formal health-care system. Jordan (1993) notes that midwife training programs are typically one sided; programs attempt to change the practices of midwives, but medical personnel do not learn about the skills and practices of traditional providers. Midwife training programs in Guatemala are frequently criticized for being tedious and unnecessarily complicated, and for using teaching methods that are culturally and situationally inappropriate for older, frequently illiterate, rural women (Cosminsky, 1982; Greenberg, 1982; Lang \& Elkin, 1997; Putney \& Smith, 1989). In addition, the nurses teaching the material often have little experience attending births, are unable to speak indigenous languages, and are condescending to the midwives.

\section{Social, economic, and cultural characteristics}

Many other factors may limit access or influence demand for health services during pregnancy. Numerous studies in developing countries have demonstrated consistent relationships between socioeconomic status and use of health services. Higher utilization of biomedical services among more educated women is believed to result in part from better allocation of financial and other resources, greater control over these resources, more autonomy in household decision-making, greater self-confidence, and stronger demand for satisfactory service from health practitioners (Caldwell, 1986; Cleland \& van Ginneken, 1988; Das Gupta, 1990). In their analysis of the Guatemala DHS, Pebley et al. (1996) demonstrate that higher levels of education are associated with increased use of biomedical care during pregnancy. Measures of income and wealth have also been shown to be important predictors of use of pregnancy care (e.g., Celik \& Hotchkiss, 2000).

Ethnicity is an important social factor in Guatemala. Two main ethnic groups each comprise roughly half of the population: the indigenous people, who are descendants of Mayan and other pre-conquest groups and maintain separate cultural identities and languages, and ladinos, who are of both indigenous and European origins, speak Spanish, and view themselves as part of the mainstream Guatemalan culture. Ethnicity is closely tied to social class: the indigenous population is, with few exceptions, poor, while ladinos are members of all social classes. Many biomedical providers do not speak an indigenous language, even when they serve a predominately indigenous population (Acevedo \& Hurtado, 1997; Goldman et al., 2001a; INCAP et al., 1997). Moreover, previous qualitative studies have indicated that medical staff in Guatemala may be condescending or discriminatory towards the poor, especially indigenous people (Cosminsky, 1982; Hurtado \& Sáenz de Tejada, 2001). Not surprisingly, indigenous women, especially non-Spanish speakers, are much less likely to use biomedical pregnancy care than ladinas (Glei \& Goldman, 2000; INE et al., 1996; Pebley et al., 1996).

Ethnic identity may also be associated with health beliefs that influence whether care is sought and whether that care is traditional or biomedical. Traditional beliefs remain common in Guatemala (Cosminsky, 1987; Scrimshaw \& Hurtado, 1988), although biomedical beliefs may be increasing (Goldman, Pebley, \& Beckett, 2001b). Previous research on child illness in Guatemala has revealed that women who hold biomedical beliefs related to the causes of diarrhea are much more likely to take their sick children to private doctors as compared with other women (Goldman \& Heuveline, 2000). These women may also be more likely than those holding traditional beliefs to seek biomedical care during pregnancy.

A woman's role in household decision-making relative to her spouse and other family members may also affect her use of health services (Bloom, Wypij, \& Das Gupta, 2001; Timyan et al., 1993). Furthermore, social ties with others may influence her decisions about seeking pregnancy care by exposing her to different ideas regarding pregnancy care and by imparting information about providers. In addition, social ties may provide access to providers that are unfamiliar to the woman, either by serving as contacts or by offering material assistance (cash or transportation). Previous research has shown that social contacts outside of her community (e.g., in larger urban areas or abroad) increase the likelihood that a woman holds biomedical beliefs about illness causation (Goldman, Pebley, \& Beckett, 2001b).

\section{Factors associated with obstetrical need}

Given the importance of previous obstetrical outcomes (e.g., stillbirth, neonatal death, or cesarean delivery) and the experience of serious complications during an ongoing pregnancy (e.g., hemorrhage or high blood pressure) for maternal and prenatal health problems (Walsh et al., 1993; WHO, 1994, 1996), targeting obstetrical services to women with these conditions would make the best use of scarce health resources. Yet, few studies in developing countries have investigated the association between obstetrical need and use of biomedical care, in part because populationbased surveys such as the DHS typically do not collect sufficiently detailed information to permit such an 
investigation. One exception is a study in Mexico (Potter, 1988) — which unexpectedly found that some common non-threatening symptoms (e.g., vomiting) led to higher use of biomedical care, whereas serious complications did not-but this study suffers from lack of data on the timing of the complications and provider visits. Hence, it is plausible that choice of care depends more on perception of risk than on the medical definition of risk. Roth (1996) argues that in Tanzania the "official" definition of maternal risk - those factors identified by national and international policy makersdo not always coincide with the risks viewed as valid at the community level.

Other studies examine the effects of prior pregnancy outcomes, but have no information about complications during the ongoing pregnancy. Bhatia and Cleland (1995) determine that a history of fetal loss or neonatal death is positively related to receiving care during the first trimester in India. Although Jahn, Kowalewski, and Kimatta (1998) find no effect of prior perinatal mortality on use of obstetrical care in Tanzania, they do find an effect of prior cesarean delivery.

The extremes of maternal age and parity (i.e., young and older ages, first born and fifth or higher parity) are associated with higher maternal morbidity and mortality (Walsh et al., 1993) and thus, may also indicate a greater need for biomedical care. At the same time, these variables may also reflect experience with pregnancyrelated matters and, as such, older and multiparous women may be less inclined to seek care. Results from the 1996 DHS in Guatemala reveal that mothers older than 25 were more likely to use biomedical care during pregnancy (Pebley et al., 1996).

\section{Data and methods}

\section{The 1995 Guatemalan Survey of Family Health (EGSF)}

In the EGSF, interviews were conducted with 2872 women aged 18 to 35 in 60 small, rural communities (i.e., between 200 and 10,000 inhabitants) within four departments of Guatemala. The departments were selected on the basis of social, economic, and environmental diversity, and ethnic composition. One department is primarily ladino (Jalapa), two are predominantly indigenous (Chimaltenango and Totonicapán), and one has a mixed population (Suchitepéquez). Communities were randomly selected with probability proportional to population size to yield self-weighting samples within departments. Versions of the questionnaire were fielded in Spanish, K'iche', and Kaqchikel. The overall response rate was $89 \%$.

A calendar design was used to collect detailed information on pregnancy-related care and complications for each of a woman's last two live births that occurred within the 5 years prior to the interview (since January, 1990) - a total of 3350 births to 2020 women. Mothers were asked about serious complications they experienced during pregnancy, and interviewers recorded the specific gestational months (1st-9th) in which each symptom was experienced. Mothers were also asked about persons that they saw during pregnancyincluding midwives, nurses, doctors, personnel at health centers and posts, and other traditional and biomedical providers - and the relevant gestational months were noted in the calendar. Subsequently, interviewers obtained information in a tabular format about each provider that the respondent reporting seeing during the pregnancy (e.g., reasons for seeing the provider, procedures used by the provider, cost). Information on family and household characteristics come from sections of the questionnaire on the respondent's background, health beliefs, social networks, economic status, and birth history.

Community informants and providers were also interviewed in each community. Three community informants (the mayor, a woman in a leadership position, and another person who knew the community well) provided information about the community (e.g., services, transportation, and migration patterns). In addition, the informants provided a listing of health providers and facilities within a $20-\mathrm{km}$ radius. The three listings were subsequently consolidated to construct a census of health providers and facilities for each community (see Peterson, Goldman, \& Pebley, 1997 for details), which formed the sampling frame for subsequent interviews with providers. The community and provider questionnaires were administered only in Spanish.

\section{Analytical strategy}

We analyze the use of prenatal care in two stages, each of which entails a binary choice: (1) obtaining any form of care during a given month of pregnancy; and (2) obtaining biomedical care in a given month of pregnancy conditional on receiving some form of care in that month. Biomedical care is defined to include health centers and posts, and private doctors and nurses. $^{2}$ Each of the two stages is modeled with a logit equation, forming a continuation ratio logit model (Agresti, 1990).

We use a multilevel logit model in the analysis for two reasons. The first concerns the nature of the sample used for estimation. The EGSF is highly clustered by community (i.e., about 50 women were interviewed in each of 60 communities). Moreover, because of the need to identify the timing of complications relative to the

\footnotetext{
${ }^{2}$ Nearly all women who saw a private nurse during pregnancy also saw a private doctor.
} 
timing of care, we use a longitudinal data set where each woman contributes observations for up to nine pregnancy months. Under these circumstances, the standard assumption of independence across women in the same community or across months of observation on the same woman is highly suspect. Conventional estimates that ignore clustering are likely to overestimate the precision of the coefficients (Goldstein, 1995; Rodríguez \& Goldman, 2001). In addition, in the case of non-linear relationships such as the logit, failure to account for clustering may lead to inconsistent parameter estimates, which are generally biased toward zero (Pebley et al., 1996; Rodríguez \& Goldman, 1995). Multilevel models provide improved estimates and correct standard errors that account for the hierarchical structure of the data.

The second motivation for using multilevel models is to derive substantive information regarding the degree to which group membership shapes individual behavior (Goldstein, 1995; Rodríguez \& Goldman, 1995). Pebley et al. (1996) documented substantial correlation in health-care choices in Guatemala: women who used a biomedical provider during one pregnancy were likely to do the same in the next, and women who lived in the same community were more similar in their patterns of prenatal care than were women in different communities. Unfortunately, the survey used for their analysis (the DHS) includes a limited range of potentially important determinants of health-care choices, a drawback that may explain the authors' inability to account for much of the observed clustering.

The multilevel model used in this analysis - a threelevel random-intercept model-incorporates a random effect at two levels other than the individual pregnancy month: the community and the pregnancy. This model is described in more detail below. Although we could have included up to two pregnancies per woman by introducing a woman-level random effect to account for correlation between the two pregnancies, we chose instead to select her most recent birth for analysis. This reduced the complexity of the model from four to three levels, making estimation more feasible. It also restricted the analysis to births that occurred relatively close to the time of interview (19 months prior to interview, on average), thereby enhancing the likelihood that mothers provided accurate information about complications and pregnancy care. Exploratory work suggested that women's behavior was very consistent across pregnancies. Therefore, the inclusion of more than one pregnancy per woman would provide little additional information, yet introduce serious difficulties in estimation. One drawback is that the random effects estimated at the pregnancy-level reflect unobserved characteristics of both the woman and the individual pregnancy, and we are unable to distinguish between them.
The final sample consists of 17,638 pregnancy months, ${ }^{3}$ with an average of 8.9 months per birth and an average of 32.8 births per community. In our notation we use $i$ to index communities, $j$ to index pregnancies (or women) within communities, and $k$ to index pregnancy months. We assume that conditional on random effects $z_{i}$ and $z_{i j}$, representing unobserved characteristics of the $j$ th community and of the $j$ th woman in that community, the provider choices are mutually independent across pregnancy months. We further assume that the logit of the conditional probability $\pi_{i j k}$ that the $j$ th woman in the $i$ th community will seek care in the $k$ th month of pregnancy given the random effects satisfies the model

$\operatorname{logit}\left(\pi_{i j k}\right)=\alpha_{k}+\boldsymbol{x}_{i j k}^{\prime} \boldsymbol{\beta}_{k}+\sigma_{\mathrm{p}} \mathrm{z}_{i j}+\sigma_{\mathrm{c}} \mathrm{z}_{i}$.

The second-stage model-for the logit of the conditional probability that the $j$ th woman in the $i$ th community sees a biomedical provider in the $k$ th month of pregnancy-has the same general structure, but with different coefficients. In Eq. (1), $\alpha_{k}$ represents the effect of month $k$ on the choice; because very few women see a provider in the first few months of pregnancy, we estimate a common effect for the first trimester and individual effects for months four through nine. The covariate vector $\boldsymbol{x}_{i j k}$ is indexed using three subscripts, but most of its elements represent characteristics that are fixed throughout the pregnancy; the single exception is an indicator of whether the woman experienced a complication in a given pregnancy month, a covariate central to our aims. The model permits the effects of the covariates to vary by duration. In order to model these interactions in a parsimonious way, we allowed the effects to vary by trimester rather than month. Incorporating these distinctions, the model can be rewritten as

$$
\begin{aligned}
\operatorname{logit}\left(\pi_{i j k}\right)= & \alpha_{k}+\boldsymbol{x}_{i j}^{(1)^{\prime}} \boldsymbol{\beta}^{(1)}+\boldsymbol{x}_{i j}^{(2)^{\prime}} \boldsymbol{\beta}_{t(k)}^{(2)}+x_{i j k}^{(3)} \beta_{t(k)}^{(3)} \\
& +\sigma_{\mathrm{p}} \mathrm{z}_{i j}+\sigma_{\mathrm{c}} \mathrm{z}_{i},
\end{aligned}
$$

where $t(k)$ represents the trimester corresponding to month $k, \boldsymbol{x}_{i j}^{(1)}$ represents the fixed covariates with constant effects $\boldsymbol{\beta}^{(1)}, \boldsymbol{x}_{i j}^{(2)}$ represents the fixed covariates with effects $\boldsymbol{\beta}_{t(k)}^{(2)}$ that vary by trimester, and finally $x_{i j k}^{(3)}$ represents our time-varying indicator of complications, with effects $\beta_{t(k)}^{(3)}$ that vary by trimester.

We assume that the random effects are independent and normally distributed with mean zero and variances $\sigma_{\mathrm{c}}^{2}$ and $\sigma_{\mathrm{p}}^{2}$ at the community and pregnancy levels, respectively. In the equations, we have written these effects as the product of their standard deviation, $\sigma_{\mathrm{c}}$ or $\sigma_{\mathrm{p}}$, and a standard normal random variable. In this formulation, the $\sigma$ 's can be interpreted as logit

\footnotetext{
${ }^{3}$ Observations with missing data on any of the explanatory variables $(2.6 \%)$ were excluded.
} 
coefficients, representing the effect of a one standard deviation change in the unobserved characteristics of the community or pregnancy, respectively. The $\sigma$ 's can also be interpreted in terms of intra-class correlations $\left(\rho_{\mathrm{c}}\right.$ and $\rho_{\mathrm{p}}$, for the community and pregnancy, respectively) in a latent variable reflecting a predisposition to seek prenatal care (or a predisposition to see a biomedical provider given that one has sought care); see Pebley et al. (1996). ${ }^{4}$ The model in Eq. (2) was estimated using maximum-likelihood procedures, based on Gauss-Hermite numerical quadrature (Rodríguez \& Goldman, 2001). ${ }^{5}$

Because of the computationally intensive nature of the estimation procedure, we were unable to estimate models with large numbers of explanatory variables. In order to obtain a relatively parsimonious model, we conducted exploratory model building in Stata (StataCorp, 2001) using ordinary logit models corrected for community-level clustering. For each of the two equations, explanatory variables (from the list provided in Table 1) that were not significant at the 0.20 level were excluded from that equation. Subsequently, multilevel models based on the remaining variables were estimated using numerical quadrature, and explanatory variables that were not significant at the 0.05 level were dropped. Consequently, in our final model, the equation representing any care does not include the same variables as the equation denoting biomedical care given any care.

\section{Explanatory variables}

We employ the behavioral model of health service use (Aday \& Andersen, 1974; Andersen, 1995; Andersen \& Newman, 1973), with minor adaptation, to provide an organizational structure for the determinants of pregnancy care. This framework specifies three categories of population characteristics that are hypothesized to have direct effects on health behavior: predisposing characteristics, enabling resources, and measures of need.

\footnotetext{
${ }^{4}$ These intra-class correlations are defined as

$\rho_{\mathrm{c}}=\frac{\sigma_{\mathrm{c}}^{2}}{\sigma_{\mathrm{c}}^{2}+\sigma_{\mathrm{p}}^{2}+\frac{\pi^{2}}{3}} \quad$ and $\quad \rho_{\mathrm{p}}=\frac{\sigma_{\mathrm{c}}^{2}+\sigma_{\mathrm{p}}^{2}}{\sigma_{\mathrm{c}}^{2}+\sigma_{\mathrm{p}}^{2}+\frac{\pi^{2}}{3}}$,

and at the community and pregnancy levels, respectively. The intra-pregnancy correlation is always at least as large as the intra-community correlation, as logic would require, and each correlation coefficient increases monotonically with the corresponding $\sigma$.

${ }^{5}$ This procedure involves using a set of S-Plus functions and routines written in $\mathrm{C}$, which were developed by Germán Rodríguez (Pebley et al., 1996; Rodríguez \& Goldman, 2001). Estimates derived in this manner avoid the biases inherent in approximate methods of inference for binary responses, used in statistical packages such as MLwiN and VARCL (Rodríguez \& Goldman, 1995).
}

Numerous variables belong in more than one of these categories. In such cases, we made an arbitrary classification for purposes of discussion and presentation of results. Below, we describe all explanatory variables hypothesized to affect pregnancy care decisions, regardless of whether they are ultimately included in the multilevel model.

\section{Predisposing characteristics}

Predisposing characteristics describe the propensity of an individual to use services. These characteristics include demographic factors, cultural factors, and variables that affect a woman's status and coping ability.

Maternal age is coded as a dichotomous variable, indicating whether the mother was below age 20 at the time of the birth. Parity is classified into three categories - first, second through fourth, and fifth or higher order-that reflect the greater health risks associated with first and high parity births.

Ethnicity is based on respondents' self-classification as indigenous or ladino and self-reported ability to speak Spanish. These questions were not asked within the department of Jalapa because the selected communities were almost entirely ladino and the pretest indicated that respondents in Jalapa took offense at these questions. Thus, all respondents in Jalapa are coded as ladino. Information on mother's health beliefs is derived from responses to a hypothetical question regarding the causes of diarrhea. Interviewers described a 2-year-old child who had experienced diarrhea (asientos) several times a day for 5 days, and then asked the respondent why she thought that the child had gotten sick; all responses were recorded. A dummy variable captures those who gave any response related to hygiene or contamination (e.g., eating dirty or contaminated things, infection, microbes), in an effort to identify mothers holding biomedical health beliefs about illness causation (Goldman et al., 2001b). Mothers who reported biomedical beliefs frequently indicated other health beliefs as well. Those who attributed diarrhea solely to causes other than hygiene or contamination such as hotcold etiology or folk illnesses form the reference group.

A woman's education is represented by the number of years of schooling that she completed. Women's autonomy in household decision-making relative to her spouse is measured by an index derived from women's responses to four questions regarding decisions about food purchases, purchases of medicine, whom the respondent should see if she is sick, and who is in charge of the money for household expenses (Seltzer, Pebley, \& Goldman, 1997). For each item, one point was assigned if the respondent indicated that she makes the decision on her own, resulting in an index ranging from zero to four with an alpha reliability of 0.64 . Because this information was asked only of women who were married or in a consensual union, the index is coded to 
Table 1

Potential covariates of pregnancy care, mean or percent in category

\begin{tabular}{|c|c|}
\hline Variable & $\begin{array}{l}\text { Mean or } \\
\text { percent }\end{array}$ \\
\hline Community level & $(n=60)$ \\
\hline $\begin{array}{l}\text { Distance from municipal capital to } \\
\text { Guatemala city (in km) }\end{array}$ & 150.4 \\
\hline $\begin{array}{l}\text { Doctor or private clinic within the community } \\
(\%)\end{array}$ & 30.0 \\
\hline $\begin{array}{l}\text { Health center or post within the community } \\
(\%)\end{array}$ & 41.7 \\
\hline $\begin{array}{l}\text { Bus service available and principle road open } \\
\text { all year }(\%)\end{array}$ & 33.3 \\
\hline $\begin{array}{l}\text { Migration abroad is common in the } \\
\text { community }(\%)\end{array}$ & 23.3 \\
\hline $\begin{array}{l}\text { Migration within Guatemala is common in } \\
\text { community }(\%)\end{array}$ & 26.7 \\
\hline Motherlfamily level & $(n=2020)$ \\
\hline Ethnicity/language $^{\mathrm{a}}$ & \\
\hline Ladina $(\%)$ & 35.0 \\
\hline Indigenous, speaks Spanish $(\%)$ & 51.9 \\
\hline Indigenous, does not speak Spanish (\%) & 13.1 \\
\hline Biomedical health beliefs $(\%)$ & 30.8 \\
\hline Highest grade completed (in years) & 2.3 \\
\hline In a marital or consensual union $(\%)$ & 91.7 \\
\hline $\begin{array}{l}\text { Autonomy in } \mathrm{HH} \text { decision-making (index } \\
\text { from } 0-4)^{\mathrm{b}}\end{array}$ & 1.0 \\
\hline $\begin{array}{l}\text { Monthly per capita household consumption } \\
\text { (in quetzales) }\end{array}$ & 23.2 \\
\hline Mother has medical insurance $(\%)$ & 4.0 \\
\hline Family has access to free medical services ( $\%)$ & 17.2 \\
\hline Family has a car or truck $(\%)$ & 7.6 \\
\hline $\begin{array}{l}\text { Has relatives in Guatemala City or another } \\
\text { country }(\%)\end{array}$ & 51.0 \\
\hline Birth level (most recent birth) & $(n=2020)$ \\
\hline Mother less than age 20 at birth (\%) & 14.6 \\
\hline \multicolumn{2}{|l|}{ Parity } \\
\hline First birth $(\%)$ & 17.5 \\
\hline Second, third, or fourth order birth $(\%)$ & 51.1 \\
\hline Fifth or higher order birth $(\%)$ & 31.4 \\
\hline Had a prior cesarean delivery $(\%)$ & 4.5 \\
\hline Had a prior neonatal death $(\%)$ & 8.8 \\
\hline Ever had a fetal loss $(\%)$ & 19.6 \\
\hline Pregnancy month level (most recent birth) & $(n=18,028)$ \\
\hline $\begin{array}{l}\text { Serious complication during the pregnancy } \\
\text { month }(\%)\end{array}$ & 2.1 \\
\hline
\end{tabular}

Note: The total number of cases is shown in parentheses, but all descriptive statistics are based on non-missing data. Missing cases comprise fewer than $2 \%$ of the total number of cases on any one variable.

${ }^{\mathrm{a}}$ Respondents in Jalapa were not asked questions about ethnicity or language ability; all were coded as ladino.

${ }^{\mathrm{b}}$ Among women in a marital or consensual union $(n=1852)$.

${ }^{\mathrm{c}}$ At the time of the survey, one quetzal was worth between 18 and 20 cents US. zero for single women and a dummy variable indicating whether or not the respondent was married or in a union at the time of the survey is included in the model.

\section{Enabling resources}

Enabling resources refer to the means available to obtain services. These factors include economic resources, insurance coverage, accessibility of services, availability of transportation, and social connections to persons outside of the community.

Our measure of household income-monthly household consumption per person in the household-is derived from women's reports regarding household consumption of 40 staples and food products bought, harvested, produced, or gathered in the 7 days preceding the survey (Gragnolati, 1998). Consumption has been shown to more accurately represent long-term household income than earnings and sales of agricultural produce, because it is less subject to short-term fluctuations (Deaton, 1989) and is likely to be more precise, especially in agricultural communities where food may be produced and consumed within the household. Another measure of wealth, which also captures access to health services, identifies respondents whose family owns a car or truck.

Two variables, derived from the census of providers and facilities, represent availability of providers: whether or not there is a private doctor or private clinic in the community, and whether or not there is a health center or post in the community. Another variable, derived from questions asked of the key informants, ${ }^{6}$ identifies communities that have had bus transport over the past 5 years and a main road open year round. Two additional dichotomous variables measure access to health care: whether the woman has health insurance, and whether anyone in the household has access to free health services (apart from health posts and centers).

Three variables depict social contact with persons outside the community. A dichotomous variable identifies women who have a relative in Guatemala City or abroad, based on responses in the individual survey. Key informants in the community survey were asked about the frequency with which people in the community leave the country and the frequency with which they move to other parts of Guatemala. Responses to these two questions were coded on a five-point ordinal scale, from which we created two dichotomous variables to

\footnotetext{
${ }^{6}$ The following strategy was used to code the communitylevel variables obtained from the three key informants in each community. If one of the informants gave a different response than the other two, the value given by the two informants was used. If all three informants gave disparate answers, the median value (for ordinal responses) or the response of the mayor or person who had lived longest in the community (for nonordinal responses) was used.
} 
identify communities where international migration (mainly to the United States and Mexico) and migration within Guatemala (other than to plantations) is common or very common.

\section{Measures of need}

These measures reflect risk factors that indicate need for specialized obstetrical care. The risk factors include a history of cesarean delivery, fetal loss, and infant mortality, as well as serious life-threatening complications.

Based on the birth history provided by mothers, dichotomous variables were created to indicate whether any of the respondent's previous births were delivered by cesarean, whether any of her previous children died during the first month of life, and whether she had ever experienced a fetal loss (miscarriage or stillbirth). The timing of fetal losses cannot be determined from data in the EGSF, but it is likely that a woman who experienced a fetal loss before the survey date did so prior to the most recent birth. As part of the calendar on pregnancy care, women were asked in non-medical terms whether they had experienced each of four serious complications during the most recent pregnancy: bleeding/hemorrhage, swelling of the hands or face (indicating preeclampsia), ${ }^{7}$ convulsions (indicating eclampsia), and premature rupture of the membranes ("the water broke early"). A dichotomous variable calculated for each pregnancy month in the sample indicates whether the woman experienced any of these four complications during the given month.

Women were also asked whether they experienced any other serious problems; the most commonly reported of these were: pain/cramps in the stomach/back/head, nausea/vomiting/lack of appetite, and other swelling. Nonetheless, we did not include these other complications in the analysis because we suspect that there is a very incomplete record of problems that were not explicitly mentioned by the interviewer, an omission that could result in biased estimates from the model.

\section{Other variables}

We also include a measure that may capture various attributes associated with the remoteness of the community: distance to Guatemala City, measured from the municipal capital via the most convenient route (not necessarily the shortest one). These data were provided by the Guatemalan Instituto Geográfico Nacional. Finally, because of the stratification of the sample by department, we incorporate a set of variables denoting the four departments in which the EGSF took place.

We include three sets of interaction terms that reflect variations in the effects of the covariates over the course of the pregnancy. We explored numerous interactions between duration (i.e., trimester of pregnancy) and the explanatory variables described above and found that

\footnotetext{
${ }^{7}$ Women were not asked specifically about hypertension.
}

only those involving parity, ethnicity, and complications significantly improved the fit of at least one of the two equations in the model. ${ }^{8}$

\section{Results}

\section{Characteristics of the sample}

The distributions of all of the explanatory variables considered for inclusion in the model are shown in Table 1 , according to whether the variables are measured at the level of the community, mother, birth, or pregnancy month. The sample is restricted to women who had a live birth in the 5-year period prior to the interview. These descriptive statistics reveal that about one-quarter of the communities in the sample experience frequent migration abroad and a similar proportion experience frequent migration to other parts of Guatemala. Fewer than half of the communities have a governmentsponsored health facility, while only $30 \%$ have a private doctor or clinic. Access to biomedical providers is further restricted by the fact that only one-third of communities have bus transport with an accessible road. Moreover, relatively few respondents have their own vehicles or have access to medical insurance or free health services (shown at the mother/family level).

As is true in most of Guatemala, the average level of education of the sample is very low (2.3 years). About two-thirds of the women in the survey are indigenous, most of whom can speak Spanish. About half of the women have relatives in the capital or abroad. Most are married and have relatively low autonomy in household decision-making, being in charge of an average of one in four household decisions. In general, families have few resources; per capita household consumption averages 23 quetzales (approximately US \$4.50) per month.

The data in Table 1 also reveal that nearly one-fifth of the women have experienced a fetal loss and $9 \%$ have had a prior neonatal death. Given that the vast majority of rural Guatemalans give birth at home, it is not surprising that few have had a prior cesarean delivery. Only two percent of women experienced one of the four specified serious complications in a given pregnancy month (but the percentage ranges from $1 \%$ in the first trimester to $3.6 \%$ in the third trimester).

\section{A description of care during pregnancy}

The types of care sought during pregnancy are shown by month of pregnancy in Table 2 . Virtually all women

\footnotetext{
${ }^{8}$ Wald tests were used to test for the joint significance $(p<0.05)$ of the interaction terms involving a given explanatory variable and dummy variables denoting the second and third trimesters of pregnancy.
} 
Table 2

Type of pregnancy care by month of pregnancy

\begin{tabular}{|c|c|c|c|c|c|c|c|c|c|c|}
\hline \multirow[t]{2}{*}{ Providers seen } & \multirow[t]{2}{*}{ Entire pregnancy } & \multicolumn{9}{|c|}{ Month of pregnancy } \\
\hline & & $1 \mathrm{st}$ & $2 \mathrm{nd}$ & $3 \mathrm{rd}$ & 4 th & 5 th & 6th & 7 th & 8 th & 9 th \\
\hline None $(\%)$ & 3.7 & 95.5 & 83.8 & 64.9 & 51.6 & 37.8 & 25.9 & 16.6 & 11.9 & 10.6 \\
\hline Midwife only (\%) & 53.5 & 2.2 & 8.7 & 19.0 & 27.6 & 37.4 & 45.6 & 52.3 & 58.0 & 63.6 \\
\hline Any biomedical provider (\%) & 42.8 & 2.3 & 7.5 & 16.1 & 20.8 & 24.9 & 28.5 & 31.0 & 30.1 & 25.8 \\
\hline Midwife and HCP (\%) & 19.5 & 0.0 & 0.5 & 2.0 & 4.7 & 7.5 & 10.3 & 12.8 & 12.6 & 10.6 \\
\hline Midwife and doctor/nurse (\%) & 9.4 & 0.0 & 0.3 & 1.2 & 1.5 & 2.5 & 3.0 & 3.9 & 4.0 & 3.3 \\
\hline Midwife and HCP and doctor/nurse (\%) & 2.0 & 0.0 & 0.0 & 0.0 & 0.1 & 0.1 & 0.2 & 0.2 & 0.2 & 0.4 \\
\hline HCP only $(\%)$ & 5.2 & 0.7 & 2.7 & 6.7 & 7.7 & 8.1 & 8.0 & 7.3 & 6.4 & 5.3 \\
\hline $\mathrm{HCP}$ and doctor/nurse $(\%)$ & 0.8 & 0.0 & 0.0 & 0.2 & 0.2 & 0.2 & 0.2 & 0.3 & 0.2 & 0.2 \\
\hline Doctor/nurse only $(\%)$ & 6.0 & 1.6 & 3.9 & 5.9 & 6.6 & 6.5 & 6.7 & 6.5 & 6.6 & 6.1 \\
\hline Number of observations & 2020 & 2019 & 2019 & 2019 & 2019 & 2019 & 2019 & 2019 & 1995 & 1900 \\
\hline
\end{tabular}

$\mathrm{HCP}=$ Health center or post.

(96\%) received some form of care during pregnancy, and about half did so in the 4th month. The proportion rises steadily with gestation, from few women receiving care during the first trimester to about $90 \%$ in the 9 th month. Whereas women are more likely to see a midwife as the pregnancy progresses, the pattern for biomedical care is more complex, rising steadily through the first few months and varying little thereafter.

The midwife is the most frequently sought provider for pregnancy care. According to Table 2, about $84 \%$ of women see a midwife at some point during pregnancy, in contrast to about $43 \%$ seeing a biomedical provider. The most frequent type of biomedical care is the combination of a health post or center in addition to a midwife. ${ }^{9}$ Notably, women who seek biomedical care during the first two trimesters are more likely to seek such care on its own rather than in conjunction with a midwife, whereas women seeking biomedical care in the last trimester tend to see a midwife as well.

\section{Providers seen by experience of serious complications}

Table 3 explores the relationship between the occurrence of serious complications in a given month and the receipt of pregnancy care in that month. ${ }^{10}$ The estimates

\footnotetext{
${ }^{9}$ These midwives typically have no medical training beyond what they may receive in the 15-day midwife training program. They should not be confused with "nurse-midwives", who are largely non-existent in Guatemala.

${ }^{10}$ If a complication and a provider visit occurred within the same gestational month, we are unable to determine whether the complication began (or the woman recognized the complication) before or after she sought care. Implicit in our interpretation of the estimates from Eq. (1) is the assumption that the complication was recognized prior to the provider visit, a reasonable assumption given that women were asked about very serious and recognizable complications.
}

reveal a clear association between the two variables, with women who experienced serious complications being about twice as likely to seek biomedical care as their counterparts. Nonetheless, both groups of women are equally likely to rely solely on a midwife. The effect of complications on the receipt of biomedical care is particularly large during the first trimester, when women with serious problems are more than five times as likely to see a biomedical provider as compared with other women. By the third trimester, the differential is modest. In the next section, we reexamine the effects of complications on the likelihood that a pregnant woman receives biomedical care using a multivariate model that controls for additional determinants of pregnancy care.

\section{Multilevel model of pregnancy care}

Table 4 shows the estimated odds ratios for statistically significant $(p<0.05)$ covariates in the multilevel hierarchical logit model. The standard deviations of the random effects along with the associated intra-class correlations are presented at the bottom of the table.

For ease of interpretation, we have also calculated predicted (or simulated) probabilities of seeking care and of visiting a biomedical provider given that a woman sought care in a given month; these predictions are based on the full sample of pregnancy months. Table 5 shows predicted probabilities for each variable in the model, calculated by: (1) setting pregnancy duration to 5 months ${ }^{11}{ }^{(2)}$ setting the variable of interest to each of its possible categories or to pre-selected values (and setting any interactions with duration accordingly); (3) leaving

\footnotetext{
${ }^{11}$ We chose 5 months because this duration marks the midpoint of pregnancy and avoids the extremely low probabilities in early pregnancy and the high probabilities in late pregnancy.
} 
Table 3

Providers seen in a pregnancy month by experience of serious complications and trimester

\begin{tabular}{|c|c|c|c|}
\hline \multirow[t]{2}{*}{ By trimester of pregnancy } & \multicolumn{2}{|c|}{$\begin{array}{l}\text { Serious } \\
\text { complication in a } \\
\text { pregnancy month }\end{array}$} & \multirow[t]{2}{*}{$\begin{array}{l}\text { Chi- } \\
\text { square } \\
\text { test }\end{array}$} \\
\hline & No & Yes & \\
\hline \multicolumn{4}{|l|}{ Total } \\
\hline $\begin{array}{l}\text { Number of pregnancy } \\
\text { months }\end{array}$ & 17,650 & 378 & \\
\hline No provider (\%) & 45.1 & 20.6 & \\
\hline Midwife only $(\%)$ & 34.6 & 38.9 & \\
\hline Biomedical provider $(\%)$ & 20.3 & 40.5 & $p<0.001$ \\
\hline \multicolumn{4}{|l|}{ First trimester } \\
\hline $\begin{array}{l}\text { Number of pregnancy } \\
\text { months }\end{array}$ & 5993 & 64 & \\
\hline No provider $(\%)$ & 81.9 & 42.2 & \\
\hline Midwife only (\%) & 9.9 & 10.9 & \\
\hline Biomedical provider $(\%)$ & 8.2 & 46.9 & $p<0.001$ \\
\hline \multicolumn{4}{|l|}{ Second trimester } \\
\hline $\begin{array}{l}\text { Number of pregnancy } \\
\text { months }\end{array}$ & 5953 & 104 & \\
\hline No provider (\%) & 38.6 & 27.9 & \\
\hline Midwife only (\%) & 36.9 & 32.7 & \\
\hline Biomedical provider $(\%)$ & 24.5 & 39.4 & $p<0.01$ \\
\hline \multicolumn{4}{|l|}{ Third trimester } \\
\hline $\begin{array}{l}\text { Number of pregnancy } \\
\text { months }\end{array}$ & 5704 & 210 & \\
\hline No provider $(\%)$ & 13.2 & 10.5 & \\
\hline Midwife only (\%) & 58.1 & 50.5 & \\
\hline Biomedical provider $(\%)$ & 28.7 & 39.0 & $p<0.01$ \\
\hline
\end{tabular}

all other variables at their observed values; and (4) setting the community and pregnancy random effects to zero. The results represent an estimate of the average probability of seeking care (or of visiting a biomedical provider among those who seek care) in the 5th month of pregnancy, for a woman in the indicated category (e.g., having a first birth), controlling for other variables.

Table 6 shows additional calculations for the subset of variables that interact with pregnancy duration, namely birth order, ethnicity, and serious complications. For these variables, we present predicted probabilities for the first trimester and for each pregnancy month thereafter. These estimates allow us to assess how much the effects change with pregnancy duration.

The estimates pertaining to the duration of pregnancy (Tables 4 and 6) confirm the pattern detected in Table 2. The likelihood that a woman visits some provider increases dramatically throughout pregnancy, with almost all women seeing a provider in their final month. In contrast, the probability that a woman visits a biomedical provider (conditional on having sought some provider) varies little by gestation.

\section{Predisposing characteristics}

Among the variables hypothesized to affect use of pregnancy care, all of the predisposing characteristics except for age of the mother (which was therefore dropped from the model) are significant in at least one of the two equations. As shown in Table 6, women expecting their first birth are more likely to receive care early in pregnancy than their multiparous counterparts. Among women who receive some care, those having their first child are also more likely to visit a biomedical provider during pregnancy (Table 5), but the differences by gestation are not significant. A similar pattern is apparent by ethnicity: ladinas are much more likely to seek early pregnancy care than indigenous women, and when they seek care, are more likely to visit a biomedical provider. Use of biomedical services is especially low among non-Spanish speaking indigenous women.

As hypothesized, women holding biomedical ideas about illness causation are more likely than their counterparts to visit a biomedical provider when they seek care, although the difference is modest. Education is one of the strongest predictors of whether biomedical care is sought. For example, we estimate that among those seeking care in the 5th month of pregnancy, only $12 \%$ of women without formal schooling visit a biomedical provider versus $42 \%$ of women with six or more years of schooling, in the presence of controls for other characteristics (Table 5). In addition, married women are much more apt than single women to seek care during pregnancy, although there is little difference in the choice of provider. Nonetheless, among women in a marital or consensual union, greater autonomy in household decision-making is related to more frequent use of biomedical care among those who received some care.

\section{Enabling resources}

Only one of the enabling factors hypothesized to affect use of pregnancy care is significant. Women living in communities characterized by frequent migration abroad are more likely than other women to receive pregnancy care, and when they do, are much more likely to use a biomedical provider. Contrary to expectation, none of the measures of access and affordability of biomedical care-biomedical services in the community, access to bus transport, vehicle ownership, health insurance coverage, access to free care, and household consumption - is significantly related to pregnancy care.

\section{Measures of need}

In contrast to the findings regarding enabling resources, indicators of need emerge as important factors in decisions pertaining to pregnancy care, particularly biomedical care. Women who had a 
Table 4

Odds ratios and random-effects parameters from a hierarchical logit model of care during a pregnancy month

\begin{tabular}{|c|c|c|}
\hline Variable & Any provider & If any: biomedical \\
\hline \multicolumn{3}{|l|}{ Duration of pregnancy ${ }^{a}$} \\
\hline (1st trimester) & - & - \\
\hline 4th month of pregnancy & $8.63 * * *$ & 1.16 \\
\hline 5th month of pregnancy & $25.62 * * *$ & $1.59 *$ \\
\hline 6th month of pregnancy & $74.20 * * *$ & $2.08 * * *$ \\
\hline 7th month of pregnancy & $34.15^{* * *}$ & $2.54 * * *$ \\
\hline 8th month of pregnancy & $64.44 * * *$ & $1.79 * *$ \\
\hline 9th month of pregnancy & $80.01 * * *$ & $0.68^{*}$ \\
\hline \multicolumn{3}{|l|}{ Predisposing characteristics ${ }^{\mathrm{b}}$} \\
\hline (1st birth) & - & \\
\hline Second, third, or fourth order birth & $0.54 * * *$ & $0.33^{*}$ \\
\hline Interaction: second trimester $\times$ second, third, or fourth order birth & $1.54 * * *$ & - \\
\hline Interaction: third trimester $\times$ second, third, or fourth order birth & $2.19 * * *$ & - \\
\hline Fifth or higher order birth & $0.40 * * *$ & 0.59 \\
\hline Interaction: second trimester $\times$ fifth or higher order birth & $1.64 * * *$ & - \\
\hline Interaction: third trimester $\times$ fifth or higher order birth & $3.81 * * *$ & - \\
\hline (Ladina) & - & - \\
\hline Spanish-speaking indigenous & $0.29 * * *$ & $0.22 *$ \\
\hline Interaction: second trimester $\times$ Spanish-speaking indigenous & $1.16^{*}$ & - \\
\hline Interaction: third trimester $\times$ Spanish-speaking indigenous & $6.36^{* * *}$ & - \\
\hline Non-Spanish-speaking indigenous & $0.16^{* * *}$ & $0.03 * * *$ \\
\hline Interaction: second trimester $\times$ non-Spanish-speaking indigenous & 0.99 & - \\
\hline Interaction: third trimester $\times$ non-Spanish-speaking indigenous & $20.70 * * *$ & - \\
\hline Biomedical health beliefs & - & $2.32 * *$ \\
\hline Highest grade of schooling completed & $1.06 * *$ & $1.83 * * *$ \\
\hline In marital or consensual union & $3.31 * * *$ & 0.39 \\
\hline Autonomy in $\mathrm{HH}$ decision-making (for women in union) & - & $1.64 * *$ \\
\hline \multicolumn{3}{|l|}{ Enabling factors } \\
\hline Migration abroad is common in the community & $1.55^{*}$ & $10.95 * * *$ \\
\hline \multicolumn{3}{|l|}{ Measures of need ${ }^{b}$} \\
\hline Had a prior cesarean delivery & - & $15.77 * * *$ \\
\hline Ever had a fetal loss & $1.32 *$ & $4.30 * * *$ \\
\hline Serious complication during the pregnancy month & $29.45 * * *$ & $3.25^{* * *}$ \\
\hline Interaction: second trimester $\times$ complication during pregnancy month & $0.11 * * *$ & - \\
\hline Interaction: third trimester $\times$ complication during pregnancy month & $0.05 * * *$ & - \\
\hline \multicolumn{3}{|l|}{ Other variables } \\
\hline Distance to Guatemala city (in $\mathrm{km}$ ) & $1.005^{* * * *}$ & $0.95^{* * *}$ \\
\hline (Jalapa) & - & - \\
\hline Suchitepéquez & $2.15^{* * *}$ & $0.07 * *$ \\
\hline Chimaltenango & $1.71 * *$ & $0.01 * * *$ \\
\hline Totonicapán & 0.70 & 0.29 \\
\hline \multicolumn{3}{|l|}{ Random effects parameters } \\
\hline Community-level standard deviation $\left(\sigma_{\mathrm{c}}\right)$ & 0.67 & 1.45 \\
\hline Pregnancy-level standard deviation $\left(\sigma_{\mathrm{p}}\right)$ & 2.20 & 5.38 \\
\hline Intra-community correlation $\left(\rho_{\mathrm{c}}\right)$ & 0.05 & 0.06 \\
\hline Intra-pregnancy correlation $\left(\rho_{\mathrm{p}}\right)$ & 0.62 & 0.90 \\
\hline Number of pregnancy months & 17,638 & 9825 \\
\hline
\end{tabular}

$* p<0.05$.

$*^{* *} p<0.01$.

$* * * p<0.001$

${ }^{a}$ Effects of duration are shown as odds ratios relative to the first trimester: $\exp \left(\alpha_{k}-\alpha_{1}\right)$ according to Eq (1). These duration effects apply to the reference category for variables that interact with duration (i.e., parity, ethnicity/language, complications).

${ }^{\mathrm{b}}$ For variables that have interactions, we present the odds ratio in the first trimester, $\exp \left(\beta_{t(1)}\right)$, and the additional effects in the second and third trimester, $\exp \left(\beta_{t(2)}-\beta_{t(1)}\right)$ and $\exp \left(\beta_{t(3)}-\beta_{t(1)}\right)$, respectively. 
Table 5

Predicted probabilities of care for the 5th month of pregnancy by selected values of covariates

\begin{tabular}{|c|c|c|}
\hline $\begin{array}{l}\text { Selected value of } \\
\text { covariate }\end{array}$ & $P$ (Any) & $\begin{array}{l}P(\text { Biomedical } \mid \\
\text { Any) }\end{array}$ \\
\hline First birth & 0.73 & 0.28 \\
\hline Second, third, or fourth birth & 0.70 & 0.21 \\
\hline Fifth or higher order birth & 0.65 & 0.24 \\
\hline Ladina & 0.84 & 0.31 \\
\hline Spanish-speaking indigenous & 0.64 & 0.19 \\
\hline $\begin{array}{l}\text { Non-Spanish-speaking } \\
\text { indigenous }\end{array}$ & 0.48 & 0.09 \\
\hline Non-biomedical health beliefs & n.a. & 0.21 \\
\hline Biomedical health beliefs & n.a. & 0.27 \\
\hline No formal schooling & 0.66 & 0.12 \\
\hline 3 years of schooling & 0.70 & 0.23 \\
\hline 6 years of schooling & 0.73 & 0.42 \\
\hline $\begin{array}{l}\text { Not married or in a consensual } \\
\text { union }\end{array}$ & 0.46 & 0.29 \\
\hline Married or in a consensual union & 0.71 & 0.23 \\
\hline Autonomy in decision-making: 0 & n.a. & 0.20 \\
\hline Autonomy in decision-making: 2 & n.a. & 0.27 \\
\hline Autonomy in decision-making: 4 & n.a. & 0.35 \\
\hline $\begin{array}{l}\text { Migration abroad is not common } \\
\text { in the community }\end{array}$ & 0.67 & 0.19 \\
\hline $\begin{array}{l}\text { Migration abroad is common in } \\
\text { the community }\end{array}$ & 0.75 & 0.38 \\
\hline No prior cesarean delivery & n.a. & 0.22 \\
\hline Had a prior cesarean delivery & n.a. & 0.46 \\
\hline Never had a fetal loss & 0.68 & 0.21 \\
\hline Ever had a fetal loss & 0.73 & 0.32 \\
\hline $\begin{array}{l}\text { No serious complication in } \\
\text { current pregnancy month }\end{array}$ & 0.69 & 0.23 \\
\hline $\begin{array}{l}\text { Serious complication in current } \\
\text { pregnancy month }\end{array}$ & 0.86 & 0.32 \\
\hline $\begin{array}{l}\text { Distance to Guatemala city: } \\
100 \mathrm{~km}\end{array}$ & 0.65 & 0.45 \\
\hline $\begin{array}{l}\text { Distance to Guatemala city: } \\
200 \mathrm{~km}\end{array}$ & 0.73 & 0.12 \\
\hline Jalapa & 0.64 & 0.46 \\
\hline Suchitepéquez & 0.78 & 0.23 \\
\hline Chimaltenango & 0.74 & 0.10 \\
\hline Totonicapán & 0.57 & 0.35 \\
\hline
\end{tabular}

Note: Probabilities are based on the model shown in Table 4. See the text for method of calculation.

n.a. = Not applicable; variable was not significant and therefore, not included in the equation.

previous cesarean delivery are much more likely to select a biomedical provider than those without such a history; among women who visit a provider in the 5th month of pregnancy, $46 \%$ of those with a prior cesarean delivery are predicted to see a biomedical provider as compared to only $22 \%$ of their counterparts (Table 5). A history of fetal loss also affects health-care choices. Women who have experienced a fetal loss are somewhat more likely to seek care than those without such experience $(73 \%$ versus $68 \%$ in the 5 th month of pregnancy), but are also considerably more likely to choose a biomedical provider when they do seek care $(32 \%$ versus $21 \%$, see Table 5).

Serious complications also have a substantial effect. Women with complications in a pregnancy month are more likely to visit a provider in that same month and are more likely to see a biomedical provider if they do seek care, as compared to women without complications. As suggested by the data in Table 3, the association between the presence of complications and the receipt of care depends upon the duration of pregnancy, although the interaction is significant only with regard to the receipt of any type of care. Women with complications in early pregnancy are much more likely to obtain care than those without complications, but the presence of complications has little effect in the final trimester (presumably because almost all women obtain care by this stage).

Further insights into the effects of complications on the types of providers seen can be gleaned by calculating the predicted probabilities that (1) a woman visits a biomedical provider in a given month and (2) a woman visits only a midwife in a given month. ${ }^{12}$ These probabilities are as follows: 0.29 and 0.57 , respectively, for those who experienced a serious complication as compared to 0.19 and 0.50 for those with no complication (data not shown). These estimates reveal that even when women experience a serious complication, they are still much more likely to rely solely on a midwife than to seek biomedical care.

\section{Other variables}

Distance to Guatemala City is significantly associated with the use of care during pregnancy, especially biomedical care. Women in more remote communities are more likely to see some provider in a pregnancy month, but when they do seek care, they are much less likely to see a biomedical one. This variable may capture the cultural and social isolation of women living in remote areas or unmeasured aspects of access to health facilities. Large differences in the likelihood of obtaining pregnancy care are also apparent across departments, perhaps due to regional variation in belief systems or unmeasured characteristics of communities and health services.

\section{Clustering}

Despite the rich set of covariates considered for inclusion in the multivariate model, the random effects are substantial. For example, the estimated $\sigma_{\mathrm{p}}$ of 5.38

\footnotetext{
${ }^{12}$ To obtain the predicted probability of seeing a biomedical provider, $P$ (Biomedical), we calculate the product of $P$ (Any) and $P$ (Biomedical $\mid$ Any) for each pregnancy month and then average across the sample of months. The probability of seeing only a midwife is the difference between $P$ (Any) and $P$ (Biomedical), also averaged across the sample of months.
} 
Table 6

Predicted probabilities of care by duration of pregnancy and selected values of covariates

\begin{tabular}{|c|c|c|c|c|c|c|c|}
\hline \multirow[t]{2}{*}{ Selected value of covariate } & \multicolumn{7}{|c|}{ Month of pregnancy } \\
\hline & 1st trimester & 4 th & 5 th & 6 th & 7 th & 8 th & 9th \\
\hline \multicolumn{8}{|l|}{$P(A n y)$} \\
\hline First birth & 0.13 & 0.52 & 0.73 & 0.87 & 0.93 & 0.96 & 0.97 \\
\hline Second, third, or fourth birth & 0.08 & 0.48 & 0.70 & 0.86 & 0.94 & 0.96 & 0.97 \\
\hline Fifth or higher order birth & 0.06 & 0.43 & 0.65 & 0.83 & 0.95 & 0.97 & 0.98 \\
\hline Ladina & 0.15 & 0.65 & 0.84 & 0.93 & 0.91 & 0.95 & 0.96 \\
\hline Spanish-speaking indigenous & 0.05 & 0.40 & 0.64 & 0.83 & 0.95 & 0.97 & 0.98 \\
\hline Non-Spanish-speaking indigenous & 0.03 & 0.25 & 0.48 & 0.71 & 0.97 & 0.98 & 0.99 \\
\hline No serious complication & 0.08 & 0.46 & 0.69 & 0.85 & 0.94 & 0.96 & 0.97 \\
\hline Serious complication & 0.62 & 0.70 & 0.86 & 0.94 & 0.96 & 0.98 & 0.98 \\
\hline$P($ Biomedical $\mid$ Any $)$ & 0.20 & 0.21 & 0.23 & 0.25 & 0.26 & 0.24 & 0.18 \\
\hline
\end{tabular}

Note: Probabilities are based on the model shown in Table 4. See the text for method of calculation.

(Table 4) in the second equation implies that the odds of seeing a biomedical provider when a woman seeks care are more than 200 times $\left(e^{5.38}\right)$ higher for a pregnancy with unobserved effects one standard deviation above the mean as compared to the average pregnancy. This high level of clustering is reflected by the extremely high values of the intra-pregnancy correlations ( 0.62 for use of any type of care and 0.90 for biomedical care given some care). These estimates reveal that a given woman is very likely to seek similar types of care throughout her pregnancy.

Although the community-level random effects are considerably smaller than the pregnancy effects, they are nevertheless sizeable, especially in light of the numerous community-level variables considered for inclusion in the model. The estimated $\sigma_{\mathrm{c}}$ of 1.45 (for biomedical care) implies that the odds of seeing a biomedical provider (given any care) are about four times higher for a woman living in a community with unobserved effects one standard deviation above the mean as compared to the average community.

\section{Discussion}

The detailed data available in the EGSF have permitted us to obtain a more thorough understanding of the interplay of a large number of factors that potentially affect women's decisions about whether to obtain care during pregnancy and what type of care to seek. Although many of the results are consistent with our hypotheses and the findings of earlier research, they reveal an unexpected and important result. The availability of private physicians and government-sponsored health facilities within communities, the accessibility of these services, and a family's ability to afford them have little effect on their decisions to use these services during pregnancy. Only one "enabling resource"-whether migration abroad is common in the woman's community - is significantly associated with using biomedical pregnancy care. This variable may reflect access to information and financial resources that facilitate obtaining health services, or it may capture a woman's exposure to different ideas about health and pregnancy care.

The lack of an association between a family's income (measured here by household consumption) and the utilization of biomedical services is not altogether surprising because many pregnant women rely on government facilities that provide services at little or no cost. What is more puzzling is the absence of a relationship between the proximity of these services and their use. One plausible explanation may be inadequate quality of biomedical care, especially in government facilities. As noted earlier, health posts and centers are often staffed by minimally trained personnel, offer a limited range of services, and typically lack critical supplies and medicines (INCAP et al., 1997). In qualitative interviews, Guatemalan women gave various reasons for their low utilization of biomedical care, including fear of the treatments, perceptions of poor quality of care, limited hours of service, greater confidence in midwives, and lack of confidence in biomedical health services (Hurtado \& Sáenz de Tejada, 2001).

In contrast to our findings related to availability and accessibility of biomedical health services, predisposing factors - which encompass an array of demographic, social and cultural attributes of women - emerge as important determinants of pregnancy care. A woman's ethnicity and educational attainment appear to be among the strongest predictors of whether she receives biomedical care during pregnancy. Ladinas and more educated women are much more likely to visit 
biomedical providers than their indigenous and less educated counterparts. Other predisposing factors that appear to be important include parity, health beliefs, marital status, and women's autonomy in household decision-making.

Failure to consider social and cultural factors in affecting pregnancy care decisions may explain in part why policies often produce ineffective health services (Justice, 1986). Previous ethnographic studies cite a number of such sociocultural barriers: fear of medical personnel (particulary ladinos), rude or condescending treatment by medical personnel, refusal of the spouse, inability of medical staff to speak indigenous languages, and (because most doctors are male) embarrassment over being examined (Cosminsky, 1987, 2001a; Hurtado \& Sáenz de Tejada, 2001).

One of the primary objectives of this paper has been to assess the extent to which a woman's obstetrical need, as indicated by negative outcomes for previous pregnancies and complications during an ongoing pregnancy, influences her decisions. The results indicate that these variables are indeed significant determinants of pregnancy care. Women with serious complications are much more likely than their counterparts to visit a biomedical provider. Yet, even these women are more likely to rely solely on a midwife than to seek a biomedical provider. As Roth (1996) points out, women's perception of pregnancy risk may be very different than the medical definition of risk.

Given the richness of data collected in the EGSF, we anticipated that this study would find lower levels of intra-cluster correlation than Pebley et al. (1996) in their analysis of the Guatemala DHS. Although we cannot compare the two sets of estimates directly (e.g., the Pebley et al. (1996) analysis included a mother-level effect while the present study includes a pregnancy-level effect), there is little doubt that the random effects estimated in this paper are large, particularly at the pregnancy level. These results suggest that the choice of pregnancy provider is determined largely by individual or family level decision dynamics that are not captured by the observed covariates. In other words, in spite of detailed information about the woman's pregnancy, herself and her family, and her community, we continue to know relatively little about why a minority seek biomedical services, often in conjunction with a midwife, while the majority rely solely on a midwife, even when faced with life-threatening symptoms. Important unmeasured factors may relate to a women's previous experience with health personnel and facilities, the influence of her spouse and other relatives, and her belief systems regarding pregnancy and appropriate care. As in other societies, decisions regarding pregnancy-related care are often heavily influenced by the spouse and other family members (Cosminsky, 2001b;
Geurts, 2001). Of particular importance may be the quality of care that women anticipate receiving from traditional and biomedical providers. Data from qualitative studies in Guatemala and other developing countries provide important clues to understanding why women prefer midwives. Although birth is a social event as well as a physiological one (Jordan, 1993), medicalization fragments the "medical" and the "social" aspects of pregnancy care (Pigg, 1997). For example, prenatal massage is highly valued by women in many Latin American countries and serves a social as well as physiological purpose, yet medical personnel often discourage the practice without a scientific rationale for doing so (Cosmisky, 2001b; Jenkins, 2001; Jordan, 1993).

These findings have important implications for health policy in Guatemala. First, the heavy reliance on midwifery care among women experiencing serious pregnancy complications suggests that pregnancy outcomes could be improved if these women were to receive timely and appropriate biomedical care. The scarcity of resources in Guatemala, and the realization that Guatemala has the institutional capacity to handle only about one-fifth of births in medical facilities (Schieber \& Delgado, 1993), necessitates such targeting of pregnancy and delivery care. Yet, these results imply that improving proximity to biomedical services is unlikely to have a dramatic impact on utilization in the absence of additional changes that improve the quality of care or reduce barriers to access. Moreover, even if access to health facilities improves, large differences by ethnicity and education level are likely to persist.

Second, current efforts aimed at incorporating midwives into the formal health-care system may need to extend their focus beyond the modification of midwife practices to consider the provision of culturally appropriate, high-quality services by traditional and biomedical providers alike. Doing so will require bridging social, cultural, and language barriers between ladinos and indigenous groups. Training programs need to be a two-way process: both types of providers need to understand and respect each other's beliefs and practices and their potential benefits. Training programs should be interactive and participatory, not lecture-style, and should be conducted by an experienced birth attendant who is able to speak indigenous languages as needed.

Midwives supply most of the pregnancy care in rural Guatemala and are likely to continue to do so. Even in cases of complications, midwives are often the first point of contact. Therefore, greater collaboration between midwives and biomedical providers provides the best avenue for ensuring that mothers and infants receive appropriate, high-quality care from both. 


\section{Acknowledgements}

We gratefully acknowledge support for this project from NICHD (Grants R01 HD27361, R01 HD31327, and P30 HD32030), and USAID (\#HRN-A-00-97000018-00) through UNC-CH (5-56127). The findings, opinions, and recommendations expressed here are those of the authors and not necessarily those of UNC-CH or USAID. The Guatemalan Survey of Family Health (EGSF) was a joint undertaking among RAND, Princeton University, and the Instituto de Nutrición de Centro América y Panamá (INCAP), directed by Dr. Hernán Delgado. We are grateful to Elena Hurtado, Marie Ruel, Hernán Delgado, and many INCAP staff for collaboration on the survey. We would also like to thank Marion Carter and two anonymous reviewers for their suggestions and comments on this manuscript.

\section{References}

Acevedo, D., \& Hurtado, E. (1997). Midwives and formal providers in prenatal, delivery, and post-partum care in four communities in rural Guatemala: Complementarity or conflict. In A. R. Pebley, \& L. Rosero-Bixby (Eds.), Demographic diversity and change in the Central American isthmus (pp. 271-326). Santa Monica, CA: RAND Corporation.

Aday, L. A., \& Andersen, R. (1974). A framework for the study of access to medical care. Health Services Research, 9(3), 208-220.

Agresti, A. (1990). Categorical data analysis. New York: Wiley.

Andersen, R. M. (1995). Revisiting the behavioral model and access to medical care: Does it matter? Journal of Health and Social Behavior, 36(1), 1-10.

Andersen, R. M., \& Newman, J. F. (1973). Societal and individual determinants of medical care utilization in the U.S. Milbank Memorial Fund Quarterly, 51, 95-124.

Bhatia, J. C., \& Cleland, J. (1995). Determinants of maternal care in a region of south India. Health Transition Review, 5, $127-142$.

Bloom, S. S., Wypij, D., \& Das Gupta, M. (2001). Dimensions of women's autonomy and the influence on maternal health care utilization in a North Indian city. Demography, 38(1), 67-78.

Caldwell, J. C. (1986). Routes to low mortality in poor countries. Population and Development Review, 12(2), 171-220.

Celik, Y., \& Hotchkiss, D. R. (2000). The socio-economic determinants of maternal health care utilization in Turkey. Social Science and Medicine, 50(12), 1797-1806.

Cleland, J. G., \& van Ginneken, J. K. (1988). Maternal education and child survival in developing countries. The search for pathways of influence. Social Science and Medicine, 27(12), 1357-1368.

Cosminsky, S. (1977). Childbirth and midwifery on a Guatemalan finca. Medical Anthropology, 1(3), 69-104.
Cosminsky, S. (1982). Childbirth and change: A Guatemalan study. In C. P. McCormack (Ed.), Ethnography of fertility and birth (pp. 195-219). New York: Academic Press.

Cosminsky, S. (1987). Women and health care on a Guatemalan plantation. Social Science and Medicine, 25(10), $1163-1173$.

Cosminsky, S. (2001). Maya midwives of southern Mexico and Guatemala. In B. R. Huber, \& A. R. Sandstrom (Eds.), Mesoamerican healers. Austin TX: University of Texas Press.

Cosminsky, S. (2001a). Midwifery across the generations: A modernizing midwife in Guatemala. Medical Anthropology, 20(4), 345-378.

Das Gupta, M. (1990). Death clustering, mother's education and the determinants of child mortality in rural Punjab. In: J. C. Caldwell et al. (Eds.), What we know about health transition: the cultural, social and behavioural determinants of health, Series No. 2, Vol. I (pp. 441-461). Australian National University, Health Transition. Canberra, Australia: Australian National University Printing Service.

Deaton, A. (1989). Savings in developing countries: Theory and review. Washington, DC: The World Bank.

Geurts, K. (2001). Childbirth and pragmatic midwifery in rural Ghana. Medical Anthropology, 20(4), 379-408.

Glei, D. A. (2001). The integration of traditional and biomedical care during pregnancy and birth in rural Guatemala [Dissertation]. Princeton, NJ: Princeton University.

Glei, D. A., \& Goldman, N. (2000). Understanding ethnic variation in pregnancy-related health care in rural Guatemala. Ethnicity and Health, 5(1), 5-22.

Goldman, N., \& Glei, D. A. (2003). Evaluation of midwifery care: Results from a survey in rural Guatemala. Social Science and Medicine, 56(4), 685-700.

Goldman, N., \& Heuveline, P. (2000). Health-seeking behaviour for child illness in Guatemala. Tropical Medicine and International Health, 5(2), 145-155.

Goldman, N., Glei, D. A., Pebley, A. R., \& Delgado, H. (2001a). Atención Prenatal en Guatemala Rural: Resultados de la Encuesta Guatemalteca de Salud Familiar. Guatemala City, Guatemala: Instituto de Nutrición de Centro América y Panamá (INCAP).

Goldman, N., Pebley, A. R., \& Beckett, M. (2001b). Diffusion of ideas about personal hygiene and contamination in poor Countries: Evidence from Guatemala. Social Science and Medicine, 52, 53-69.

Goldman, N., Pebley, A. R., \& Gragnolati, M. (2002). Choices about treatment for ARI and diarrhea in rural Guatemala. Social Science and Medicine, 55(10), 1693-1712.

Goldstein, H. (1995). Multilevel statistical models. London, UK: Edward Arnold.

Gragnolati, M. (1998). Documentation for measure of per capita household expenditure. Appendix E. In C. Peterson, N. Goldman, \& A. R. Pebley (Eds.), The 1995 Guatemalan Survey of Family Health (EGSF): Overview and codebook. Santa Monica, CA: RAND.

Greenberg, L. (1982). Midwife training programs in highland Guatemala. Social Science and Medicine, 16(18), 1599-1609.

Hurtado, E., \& Sáenz de Tejada, E. S. (2001). Relations between government health workers and traditional 
midwives in Guatemala. In B. R. Huber, \& A. R. Sandstrom (Eds.), Mesoamerican healers. Austin, TX: University of Texas Press.

Instituto de Nutriciónde Centro América y Panamá (INCAP), Ministerio de Salud Pública y Asistencia Social (MSPAS), USAID, DHS/Macro International. (1997). Salud Materno Infantil en Cuatro Departmentos de Antiplano. Resultados de la Encuesta de Proveedores de Salud, 1997. Guatemala City, Guatemala: INCAP.

Instituto Nacional de Estadistica (INE), Ministerio de Salud Pública y Asistencia Social (MSPAS), USAID, UNICEF, and Demographic and Health Surveys (DHS). (1996). Guatemala: Encuesta Nacional de Salud Materno Infantil, 1995. Calverton, MD: DHS/Macro International Inc.

Jahn, A., Kowalewski, M., \& Kimatta, S. S. (1998). Obstetric care in southern Tanzania: Does it reach those in need? Tropical Medicine and International Health, 3(11), 926-932.

Jenkins, G. (2001). Changing roles and identities of midwives in rural Costa Rica. Medical Anthropology, 20(4), 409-444.

Jordan, B. (1993). Birth in four fultures: A crosscultural investigation of childbirth in Yucatan, Holland, Sweden, and the US. Prospect Heights, IL: Waveland Press.

Justice, J. (1986). Policies, plans, and people: Foreign aid and health development. Berkeley: University of California Press.

Lang, J. B., \& Elkin, E. D. (1997). A study of the beliefs and birthing practices of traditional midwives in rural Guatemala. Journal of Nurse Midwifery, 42(1), 25-31.

Leedam, E. (1985). Traditional birth attendants. International Journal of Gynaecology Obstetrics, 23(4), 249-274.

Mahler, H. (1987). The safe motherhood initiative: A call to action. Lancet, 1(8534), 668-670.

MotherCare. (1997). MotherCare/Guatemala. MotherCare Matters, 6(4) 10-15.

National Research Council (NRC). (1997). Healthy pregnancy and childbearing. In: A. O. Tsui, J. N. Wasserheit, \& J. G. Haaga (Eds.), Reproductive health in developing countries: Expanding dimensions, building solutions (pp. 116-145). Washington, DC: National Academy Press.

Pebley, A. R., Goldman, N., \& Rodríguez, G. (1996). Prenatal and delivery care and childhood immunization in Guatemala: Do family and community matter? Demography, 33(2), 231-247.

Peterson, C., Goldman, N., \& Pebley, A. R. (1997). The 1995 Guatemalan Survey of Family Health (EGSF): Overview and codebook. Santa Monica, CA: RAND.

Pigg, S. L. (1997). Authority in translation: Finding, knowing, naming, and training "traditional birth attendants" in Nepal. In R. E. Davis-Floyd, \& C. F. Sargent (Eds.), Childbirth and authoritative knowledge (pp. 233-262). Berkeley, CA: University of California Press.

Potter, J. (1988). Utilización de los Servicios de Salud Materna en el México Rural. Salud Pública de México, 39(3), 387-402.

Putney, P. J. \& Smith, B. (1989). The training and practice of traditional birth attendants in Guatemala. Unpublished report. Technologies for Primary Health Care (PRITECH) Project, supported by USAID (PN ABF-275).

Rodríguez, G., \& Goldman, N. (1995). An assessment of estimation procedures for multilevel models with binary responses. Journal of the Royal Statistical Society, 158(1), 73-89.

Rodríguez, G., \& Goldman, N. (2001). Improved estimation procedures for multilevel models with binary response: A case study. Journal of the Royal Statistical Society, 164, 339-355.

Roth, D. M. (1996). Bodily risks, spiritual risks: Contrasting discourses on pregnancy in a rural Tanzanian community. Dissertation. Urbana-Champaign, IL: University of Illinois at Urbana-Champaign.

Safe Motherhood Intra-Agency Group (IAG). (2000). What is safe motherhood? Retrieved August 21, 2000 from the World Wide Web: http://www.safemotherhood.org/init_action_ messages.htm/. New York, NY.

Schieber, B., \& Delgado, H. (1993). An intervention to reduce maternal and neonatal mortality: INCAP Publication. M1-003. Guatemala City, Guatemala: INCAP/ PAHO.

Scrimshaw, S. C. M., \& Hurtado, E. (1988). Anthropological involvement in the Central American diarrheal disease control project. Social Science and Medicine, 27(1), 97-105.

Seltzer, J. A., Pebley, A. R., \& Goldman, N. (1997). Wives' role in household decision-making in rural Guatemala. Paper presented at the annual meetings of the Population Association of America, March 27-29, Washington, DC.

Sesia, PM. (1997). Women come here on their own when they need to. In R. E. Davis-Floyd, \& C. F. Sargent (Eds.), Childbirth and authoritative knowledge: cross-cultural perspectives (pp. 397-420). Berkeley, CA: University of California Press.

StataCorp. (2001). Stata Statistical Software: Release 7.0. College Station, TX: Stata Corporation.

Sundari, T. K. (1992). The untold story: How the health care systems in developing countries contribute to maternal mortality. International Journal of Health Services, 22(3), 513-528.

Timyan, J., Brechin, S. J. G., Measham, D. M., \& Ogunleye, B. (1993). Access to care: More than a problem of distance. In M. Koblinsky, K. Timyan, \& J. Gay (Eds.), The health of women: A global perspective (pp. 217-234). Boulder, CO: Westview Press.

Villatoro, E. \& Hurtado, E. (1986). Informe Final de la Investigación Etnográfica sobre Algunos Aspectos de Salud y Nutrición Realizada en una Comunidad de Hueheutenango. Unpublished report. Prepared for Guatemalan Ministry of Public Health and Social Assistance, Guatemala City.

Walsh, J. A., Feifer, C. N., Measham, A. R., \& Gertler, P. J. (1993). Maternal and prenatal health. In D. T. Jamison, W. H. Mosely, A. R. Measham, \& J. L. Bobadilla (Eds.), Disease control priorities in developing countries (pp. 363390). Oxford: Oxford University Press.

World Bank. (1999). World development indicators, 1999. Washington, DC: World Bank. Retrieved 24 November 1999 from the World Wide Web: http://www.worldbank. org/data/wdi/.

World Health Organization (WHO). (1994). Antenatal care. Report of a Technical Working Group. WHO/FRH/MSM/ 96.8. Geneva: WHO. Retrieved 22 February 2000 from the 
World Wide Web: http://www.who.int/rht/documents/ MSM96-8/msm968.htm.

World Health Organization (WHO). (1996). Care in normal birth: a practical guide. Report of a Technical Working Group. WHO/FRH/MSM/96.24. Geneva: World Health Organization. Retrieved 17 February 2000 from the World Wide Web: http://www.who.int/rht/documents/MSM96-24/ msm9624.htm.
World Health Organization (WHO). (2001). Basic health indicators (country-reported data). Geneva: World Health Organization. Retrieved 16 January 2001 from the World Wide Web: http://www-nt.who.int/whosis/ statistics/.

WHO and UNICEF. (1996). Revised 1990 estimates of maternal mortality: A new approach by WHO and UNICEF. Geneva: World Health Organization. 